\section{História do Jornalismo: contingência inexorável}

atende aos conceitos de jornalismo defendidos pelo professor, de que a grande vocação dessa fatia comunicativa é "(...) estar ancorado nas realidades nacionais que lhe dá sentido e das quais se nutre cotidianamente” (p. 9). Assim, para entender a amplitude da dessa produção é primordialmente necessário revisitar as contribuições do autor ao pensamento jornalístico.

O percurso de pesquisa e de escolha profissional Maria Cristina GOBBI ${ }^{1}$

MARQUES DE MELO, José. História do Jornalismo. Itinerário crítico, mosaico contextual. São Paulo: Paulus, 2012.

Contar a História do Jornalismo, trazendo novos atores, acontecimentos e perspectivas é um mérito para poucos. Quanto vislumbrei o livro, a princípio acreditei tratar-se de mais uma publicação que trazia basicamente dados sobre o desenvolvimento da Comunicação Social, da imprensa ou mais diretamente dos estudos midiáticos, tendo o jornal como foco, evidenciando a confusão que alguns estudiosos engendram com a história do jornalismo.

Porém, caracterizar os fatos históricos que dão identidade ao jornalismo brasileiro, a partir de itinerários próprios, personagens e polêmicas que nascem das demandas sociais é um desafio que exige muito além de tempo e de dedicação, mas maturidade acadêmica. Os apontamentos, análises, comentários e informações dos textos do professor José Marques de Melo reunidos nesta obra representam a socialização de um conhecimento construído ao longo de, até então, mais de cinquenta anos dedicados à prática e aos estudos do Jornalismo e quase setenta anos de vida.

Como o próprio autor menciona, a obra não objetiva ser um contraponto com outros escritos de reconhecido valor. Mas é resultado de uma vivência de pesquisas e da coleção de registros didáticos, que formaram um arsenal de fatos do cotidiano nacional. Tal acepção 1 Pesquisadora, Pós-Doutora pelo Programa de Integração da América Latina (PROLAM) da Universidade de São Paulo. Vice-coordenadora e professora do Programa de Pós-Graduação em Televisão Digital: Informação e Conhecimento da Universidade Estadual Paulista (UNESP) e Professora do Programa de Pós-Graduação em Comunicação, da mesma instituição. Coordenadora do Grupo de Pesquisa "Pensamento Comunicacional Latino-Americano" do CNPq. Diretora Administrativa da Socicom. Coordenadora do GT Mídia, Culturas e Tecnologias Digitais na América Latina da Intercom. Email: mcgobbi@terra.com.br. pesquisa brasileira em jornalismo começou nos finais do século XIX, com a publicação de trabalhos de historiadores como o barão de Studart, Max Fleuss, Afonso de Freitas, Moreira de Azevedo, Vale Cabral, Craveiro Costa e, muito especialmente, Alfredo de Carvalho”.

Entre a cognição, no sentido do saber estocado sobre os fenômenos jornalísticos e as pesquisas capazes de gerar conhecimento cumulativo, está à práxis jornalística brasileira, que traz o saber legitimado, apontando as tendências e definindo matizes de um saber consolidado.

Marques de Melo divide o livro História do Jornalismo em três partes, onde a última faz um resgate fundamental das contribuições de atores brasileiros para a construção da história do jornalismo.

Como ponto de partida, o mestre traz aquilo que ele chama de "gênese polêmica", apontando de forma circunstanciada nomes de jornalistas paradigmáticos como Hipólito da Costa, Evaristo da Veiga e Frei Caneca, e o reconhecimento de Francisco Souza Martins, piauiense, bacharel em Direito, mas que enveredou pela política como deputado e governador e o artigo publicado em 1846, pela Revista do Instituto Histórico e Geográfico do Brasil, que tem como título "Progressos do Jornalismo 
no Brasil", situando o trabalho como um marco da pesquisa em jornalismo no Brasil (p. 22).

Igualmente, aponta outras contribuições, como as pesquisas realizadas por Moreira de Azevedo (1865), Nascimento Feitosa (1867), Duarte Pereira (1883), Pereira da Costa (1891), Alfredo de Carvalho (1899), Barbosa Lima Sobrinho (1923) e Max Fleuiss (1922), com o primeiro inventário “(...) do conhecimento acumulado sobre a imprensa” (p. 23). Para Marques de Melo é neste contexto que o Jornalismo passa a ser pesquisado como um processo sócio-político-econômico e posteriormente, com a incorporação dos trabalhos de Hélio Viana (1945) e Carlos Rizzini (1946) e a fundação dos primeiros cursos de jornalismo no país, se torna um campo legítimo de estudos.

Assim, nesse cenário inicial, Marques de Melo periodiza a história do conhecimento jornalístico brasileiro em cinco fases. Fase 1 - Pensamento: 1808 - 1858 o jornalismo como tema de reflexão; Fase 2 - Memória: 1859 - 1922 o jornalismo como tópico de observação; Fase 3 Pesquisa: 1923 - 1946 o jornalismo como objeto de cognição; Fase 4 - Disciplina: 1947 - 1992 o jornalismo como área acadêmica e finalmente, a fase 5 - Comunidade: 1993 - atualidade o jornalismo como colégio invisível (p. 24) e define 3 períodos cronológicos: 1. Emancipação - séc. XIX; 2. Identificação - séc. XX e 3. Autonomização séc. XXI, evidenciando que cada fase e cada período “(...) florescem correntes de ideias que se complementam ou confrontam, sem produzir rupturas substantivas" p. 49.

Mas um dos maiores contributos da publicação são a análise e o resgate do artigo "A imprensa no Brasil”, publicado em 20 de novembro de 1859, pelo historiador Joaquim Caetano Fernandes Pinheiro, na Revista Popular. Para Marques de Melo, mais do que ter sido um marco para o futuro campo do Jornalismo no país, a época, o material evidencia - como afirma o professor -, que mesmo com o nascimento tardio da imprensa brasileira já havia um exercício crítico sobre o oficio.

Nas páginas seguintes além de um breve perfil de figuras importantes na constituição do campo, traz um texto histórico dos personagens, como uma espécie de impressão digital sobre os estudos empreendidos por cada um, evidenciando as teses e as antíteses defendidas, complementando com uma parte "para entender melhor", onde disponibilizada outras referências bibliográficas para um conhecimento mais aprofundado sobre cada mote defendido.
Passa pela institucionalização do jornalismo pelo campo universitário, pelo controle da informação como “(...) episódio recorrente na fisionomia cultural brasileira” (p. 143), traçando as múltiplas faces da síndrome da mordaça. Também aponta as tendências atuais, fazendo um resgate das fontes que ele chamou de "(...) mais adequadas para que os novos praticantes e estudiosos compreendam suas mutações, continuidades e ressurgências neste limiar do século XXI” (p. 162).

$\mathrm{Na}$ segunda parte do volume "Conjunturas", traz a contribuição do norte-americano Robert Park e do brasileiro Barbosa Lima Sobrinho para o estudo científico do Jornalismo, propiciando uma visão comparativa entre dois cenários aparentemente tão distantes, mas que buscam na práxis jornalística oferecer o espírito público, fortalecido pela ideia de um mundo melhor, como afirma o autor (p. 217).

A próxima etapa resgata uma das grandes paixões do autor. São as pesquisas que trazem como mote central os gêneros jornalísticos. Esse foco de investigação tem atraído a atenção de Marques de Melo desde os anos de 1980. Foi precisamente em 1983 que ele defendeu a pesquisa "Gêneros Opinativos na imprensa brasileira", conquistando o título de Livre-Docente em Jornalismo, pela Escola de Comunicações e Artes da Universidade de São Paulo (Eca-USP). As pesquisas de José Marques de Melo nessa temática também podem ser encontrados nas obras “A Opinião no jornalismo brasileiro”, de 1985, depois, em sua segunda edição, revista, publicada em 1994, tendo como título "A opinião no jornalismo brasileiro". Finalmente, em 2003, a terceira edição sob o título "Jornalismo opinativo: gêneros opinativos no jornalismo brasileiro" que foi revista e ampliada. Há também, nessa linha de estudos sobre os gêneros, a publicação "Gêneros jornalísticos na Folha de S. Paulo”, de 1992, além de outros trabalhos apresentados em coletâneas e livros como "Jornalismo brasileiro (2003); Teoria do jornalismo: identidades brasileiras (2006)", afora as pesquisas apresentadas e publicadas em diversas revistas científicas e congressos nacionais e internacionais. Em seus diversos estudos Marques de Melo afirma e afiança que os gêneros jornalísticos são expressões do campo, e que mesmo sofrendo influência externa assimilam as peculiaridades nativas da região.

Em Jornalismo Científico, além de trazer as contribuições da ABJC (Associação Brasileira de Jornalismo Científico) e de outras instituições, Marques de Melo disponibiliza um lista de textos acadêmicos escritos por ele, 
bem como de outros estudiosos nesse campo do conhecimento.

O deslumbramento midiático, presente na parte que trata da "História da digitalização: euforia inclusiva" evidencia como a mídia impressa e eletrônica vem se dedicando ao advento da sociedade digital. Para o autor, a euforia causada pelas tecnologias perpassa, por vezes, o entendimento da ambiguidade conceitual que estão sujeitas e que ainda não logram em resolver. Evidencia, de forma substanciosa e linear, os primeiros estudos e os novos temas que tem arrebatado um contingente bastante significativo de pesquisadores e estudantes. E no final faz um alerta de que as pesquisas sobre políticas públicas, voltadas para a inclusão social, tão alardeada pelo uso das tecnologias digitais, “(...) devem estar incluídas nas atividades de ensino e pesquisa de nossas universidades" ( $p$. 310).

A terceira e última parte da publicação, que o autor chamou de "Narradores", faz uma agradável viagem pelas contribuições de atores paradigmáticos do campo de estudos do jornalismo, atribuindo a esses personagens adjetivos que os qualificam por seus aportes no cenário nacional. Assim, traz Hipólito da Costa, como precursor; Alfredo de Carvalho, como desbravador; Costa Rêgo, como educador; Carlos Rizzini, como pesquisador; Danton Jobim, como scholar; Luiz Beltrão, como renovador; Nelson Werneck Sodré, como inovador e finalmente a professora Marialva Barbosa, como a sucessora.

Para encerrar, em a "Reinvenção do campo", evidencia uma aparente corrente "apocalíptica”, parafraseando Umberto Eco, que carregados de pessimismo profetizam a morte do jornalismo, especialmente pelas controvérsias geradas pela indefinição da "identidade" do campo. Marques de Melo responde que um dos grandes desafios, especialmente dos novos profissionais, é o resgate do jornalismo popular, “(...) destinado às classes subalternas” e para atender esse clamor popular por informação de qualidade, de forma democrática, capaz de promover a inclusão digital e o desenvolvimento da cidadania é necessário que a pesquisa assuma seu papel social, e para isso é necessário que as pesquisas sejam realizadas “(...) com atenção redobrada, nesta segunda década do século XXI, a fim de encontrar soluções plausíveis” para as novas demandas. Para o professor Marques de Melo, trata-se de contingência inexorável.

A publicação deste livro concretiza mais uma etapa desta tarefa de compreensão, discussão e divulgação das concepções que fundamentaram a práxis e o pensamento jornalístico legitimando historicamente o processo informativo. Tarefa que somente um pesquisador com a capacidade produtiva e integradora do professor Dr. Marques de Melo poderia empreender. Também, missão esta que a muito carece nosso jornalismo, de artífices para evidenciar, dimensionar, desenhar e redesenhar o mapa evolutivo desse campo de estudos, uma vez que, infelizmente, ainda utilizamos indiscriminadamente obras forâneas para entender o desenvolvimento e a identidade do Jornalismo Brasileiro.

É um livro que atende não somente professores e estudantes do campo da história do Jornalismo, da Comunicação e suas nuances, mas amplifica o olhar para temas, debates, definições e contextos dos estudos e da prática jornalística do Brasil. 